\title{
La guerra de Bosnia: ¿Fue guerra civil o conflicto internacional?
}

\section{Lidia Padrós}

El conflicto de Bosnia-Herzegovina (desde abril de 1992 hasta noviembre de 1995) mostró que la vieja Europa no estaba exenta de la barbarie bélica que se creía stuperada después del Holocausto. ¿Pero se trató de una guerra civil, y por lo tanto, de un asunto doméstico entre nacionales donde el Derecho Internacional Público presenta los principios de "no injerencia en asuntos internos" y de "soberanía nacional"? ¿O fue un conflicto internacional, tomado en cualquiera de sus dos acepciones, es decir, en un primer sentido, como una agresión de uno o varios estados soberanos contra otro país, o en su segundo significado, como un estallido bélico en el que podian verse involucrados varios estados?

En este artículo se plantea la hipótesis de que el bosnio fue también un conflicto internacional, en los dos sentidos antes mencionados. $Y$ es que, aparte de la pura elucubración intelectual que supone plantear el tema, la cuestión tiene trascendencia si se considera que una más pronta percepción en este sentido por parte de la comunidad internacional pudiera haber proporcionado una intervención con mayor rapidez y eficacia.

\section{La actuación de algunas organizaciones internacionales}

Tres años y medio de combates, 200.000 muertos, 25.000 desaparecidos, 2.300.000 desplazados y refugiados (de una población inicial de 4.400.000), 20.000 mujeres violadas ', unos dos millones de minas esparcidas anárqui-

\footnotetext{
- Segün las estimaciones de la comisión de investigación de la Unión Europea y de la Comisión de Expertos de Naciones Unidas, las víctimas serian unas 20.000 mujeres, aunque el gobierno de Bosnia ha documentado más de 30.000. Ver: "Rape as Warfare". Transition, Noviembre, 1995. P.20.
} 
camente, y un sinfín de daños físicos, psicológicos y materiales, quizás podrian haberse evitado con una detección temprana y una mayor coordinación por parte de algunos actores intemacionales. En este sentido, discernir cuales fueron las consideraciones de la ONU, la CEE/UE, la Conferencia para la Seguridad y la Cooperación en Europa (CSCE), la Organización para la Seguridady la Cooperación en Europa (OSCE), la OTAN y la UEO, asi como de algunos estados como EEUU, Rusia, Alemania y Francia, será fundamental para inducir algunas observaciones al respecto.

Las Naciones Unidas, por su talante mundial, y concretamente el Consejo de Seguridad como órgano directivo a quien los firmantes de la Carta otorgaron la potestad de decidir cual era el mejor modo de "preservar la paz y la seguridad internacional" (art. 1.1), actuaron de forma dicotómica, según se trató del ámbito resolutivo (teórico) o sobre el terreno (práctico).

En el plano resolutivo, el Consejo de Seguridad distó de ser ambiguo pues a través de sus Resoluciones se desprendió su consideración sobre la responsabilidad de algunas de las partes. Así pues, a lo largo de 1992-1994 (recordemos que a partir de esta fecha y hasta el final de la guerra la organización se inhibió y el Grupo de Contacto fue quien asumió el rol negociador), se dictaron 55 Resoluciones de las cuales 15 lo eran contra el lado serbio, 4 contra el croata y ninguna contra los bosniomusulmanes ${ }^{2}$. Aparte del dato puramente cuantitativo, existen otras evidencias de la postura de la ONU entre las que podríamos destacar:

a) Que mediante la Resolución 752 (15 de mayo de 1992) se exigió explícitamente al Ejército Popular Yugoslavo (EPY) y a las unidades paramilitares croatas que se retirasen del territorio bosnio.

b) Que en abril de 1992, Eslovenia, Croacia y Bosnia fueron invitadas a formar parte de la Asamblea de Naciones Unidas, mientras que a Serbia y Montenegro, que también lo habían solicitado, se las instó a cumplir las resoluciones antes dictadas (Res. 777 de septiembre de 1992). De hecho, estas entidades no fueron reconocidas con el nombre de República Federal de Yugoslavia (RFY) hasta 1996, después de la firma de los Acuerdos de Dayton.

c) Que las sanciones económicas y culturales fueron dictadas contra Serbia y Montenegro (Resoluciones 757, 787, 820), y tampoco fueron levantadas hasta los Acuerdos de Paz.

\footnotetext{
${ }^{2}$ Garde. P. "Ex Yougoslavie: le fiasco de la "communauté internationale". Politique Internationale, $n^{\circ} 68$,
} 1995. P.169. 
d) Que los seis "enclaves de seguridad" decretados en 1993; Sarajevo, Bihac, Gorazde, Tuzla, Srebrenica, y Zepa, estaban en territorio bosnio-musulmán para proteger a la población de esta comunidad.

e) y finalmente, el hecho de que la mayoría de los $79^{3}$ incriminados por el Tribunal Penal Internacional (TPI) de La Haya, creado en 1993 (Res. 808) con el doble objetivo de castigar y disuadir a los presuntos criminales, fuesen de origen serbio y en menor medida croata, parecen confirmar que el nivel resolutivo distaba de ser vago.

Sobre el terreno cabe destacar el embargo general de armas impuesto en Noviembre de 1991 a la ex-Yugoslavia que constituyó un fracaso en varios aspectos, como por ejemplo el favorecimiento del bando serbio que había heredado el ejército de la antigua República y la situación de desprotección, por tanto, de los bosniomusulmanes al tener que crear una nueva estructura castrense. La no vigilancia del Danubio, que era donde más se incumplía la medida, y la concentración en el Adriático de las operaciones navales y marítimas de custodia, fue también una medida arduamente criticada. Con todo, el aspecto más controvertido fue la contradicción que supuso mantener dicho embargo tras el reconocimiento de Bosnia como estado soberano en abril de 1992, ya que representaba "de facto", negarle el derecho a la autodefensa (art. 51 de la Carta) al nuevo país.

Pero sin duda, el mayor descalabro lo protagonizó la actuación de UNPROFOR (United Nations Protection Forces). Creadas en febrero de 1992 (Res. 741 y 743), estas fuerzas tenían los objetivos de imponer el alto el fuego, hacer llegar la ayuda humanitaria, y posteriormente proteger las "áreas seguras" y los "pasillos de seguridad". Su mandato fue catalogado como de "Peace Keeping" y "Peace Building" 5 , es decir, como misión de mantenimiento de la paz y de construcción de la paz, según la tipificación de $U n$ Programa de Paz del entonces Secretario General de la ONU. Por tanto, sobre el territorio se desplegaron en total 40.000 cascos azules de una treintena de nacionalidades ${ }^{6}$ que actuaban bajo el imperativo de neutralidad, no ha-

\footnotetext{
${ }^{3}$ Sobre la situación de los presuntos culpables de cometer crímenes contra la humanidad y violar los convenios de Ginebra, ver: http://www.hrw.org/campaigns/bosnia/map

${ }^{4}$ Las operaciones de mantenimiento de la paz suponen el envio de efectivos policiales, militares y civiles de Naciones Unidas para preservar y forzar a hacer cumplir la paz con el consentimiento de las partes. s Las misiones de construcción de la paz pretenden cimentar la ausencia de guerra a través del desarme de contendientes, la repatriación de refugiados, ayudando a la formación del nuevo personal de seguridad, mediante la observación de elecciones y de la protección de los derechos humanos.
} 
ciendo distinciones entre ninguno de los bandos. Y es que, ¿cómo podía preservarse una paz que no existía? ¿Cómo podía imponerse la paz en el campo de batalla sin hacer distinción entre agresores y agredidos, sin poder usar las armas sino se recibía un ataque directo previo, y si no se contaba con un armamento suficiente, ni con un mandato preciso?

La operación fue un fracaso desde su diseño, y así fueron cayendo, una tras otra, las UNPAS ("United Nations Protected Areas" o "zonas seguras") en manos de los serbiobosnios. Igualmente, los pasillos humanitarios fueron ineficaces, los alimentos y medicinas para socorrer a la población civil no llegaron siempre a sus destinatarios, y las sucesivas órdenes de retirada del armamento pesado, fueron incumplidas.

Esta caótica situación culminó con la toma de 370 cascos azules como rehenes de las tropas serbiobosnias de R. Mladic, en julio de 1995. Los aliados se vieron sumidos en una situación de crisis ante la humillación de tener que "salvar a los salvadores".

Y es que, ni aún cuando la ONU permitió el uso de la fuerza para hacer cumplir las encomiendas de las misiones de protección (la primera a través de la Res. 836 de marzo de 1993), no se pusieron los medios necesarios ni se estuvo dispuesto a hacer efectiva dicha medida.

Ante tal cataclismo y dado que no se supieron o quisieron tomar medidas políticas al respecto, el ACNUR (Alto Comisionado de Naciones Unidas para los Refugiados) proporcionó una faraónica respuesta humanitaria, que no por gigante dejó de ser insuficiente, habiendo de padecer la población civil, los mayores prejuicios de la contienda bélica. Desde los albores del conflicto, el DAH (Departamento de Asuntos Humanitarios) coordinó la acción de las diferentes organizaciones internacionales humanitarias para dar socorro y alivio, hasta después de los Acuerdos de Dayton. En 1992, los desplazados internos y refugiados eran casi $1.500 .000, \mathrm{y}$ al terminar el conflicto la cifra se elevaba ya a $2.500 .000 .^{7}$

La Comunidad Europea estaba sumida en un proceso de transformación

\footnotetext{
${ }^{6}$ El despliegue de Unprofor resultó más costoso que el de Camboya o Somalia con un presupuesto anual de 19 millardos de $\$$. "Conflits fin de siècle". Manière de voir, $n^{\ell} 29$. Le Monde Diplomatique, Febrero de 1996 P.15.

7 Durante cuatro años, la ACNUR y otras agencias internacionales ayudaron diariamente a cerca de tres millones de personas en la ex-Yugoslavia, la mayoria en Bosnia. Al terminar el conflicto, sólo unas 80.000 personas se desplazaron a otro lugar distinto del que estaban refugiadas o desplazadas, frecuentemente a zonas donde su comunidad era mayoritaria.
} 
interna hacia una Unión Europea que pondría en marcha un mercado común. Ante esta situación de "euroforia", el conflicto en la ex-Yugoslavia se vio, en un primer momento, como la ocasión ideal para empezar a practicar una acción común europea en un asunto del propio continente. De este modo, el Presidente de la Troika ${ }^{8}$ de turno, el luxemburgués J. Poos, declaró que había llegado "la hora de Europa".

La CEE/UE actuó a través de tres líneas de conducta, según se fueron desarrollando los hechos. En 1991-92, el Consejo Ministerial de los Doce, actuando a través de la CPE (Cooperación Política Exterior), no aceptó la desmembración del estado yugoslavo, y aunque el "Memorándum de Brioni" se presentó como un éxito de la diplomacia europea, resultó ser, en realidad, una simple tregua. ${ }^{9}$

La segunda senda de actuación supuso el reconocimiento de las independencias. En la Conferencia de Paz de La Haya, presidida por Lord Carrington, se propuso convertir el estado en una confederación asimétrica en la que cada una de las 6 repúblicas tendría tanta independencia como quisiera, como habían propuesto ya los presidentes de Bosnia-Herzegovina y de Macedonia, Izetbegovic y Gligorov, respectivamente. El plan fue rechazado ya que el proyecto panserbista incluía hacerse con el estado yugoslavo en su totalidad.

Posteriormente, la Comisión Badinter, formada por los presidentes de los Tribunales Constitucionales de cinco estados europeos, emitió tres dictámenes. En el primero se constataba el proceso de disolución de la ex-Yugoslavia y se instaba a las repúblicas que quisieran optar por la independencia a cumplir ciertas garantías (como el respeto a la minoría serbia que habitaba en Croacia). En el segundo, se puntualizaba que las minorías serbias que vivían en Bosnia no podían independizarse. Y en el último, se aplicó el principio de "uti possidetis" 10 como criterio delimitador de las seis entidades del estado que podían optar a la autodeterminación."

\footnotetext{
${ }^{8}$ Recordemos que la Troika europea está formada por el presidente de turno, su inmediato antecesor y su sucesor. En ese momento, la Troika la formaban los representantes de Luxemburgo, Holanda e Italia. 9 Moreau Defarges P. "Les Organisations Internationales et la crise yugoslave", en Politique Étrangère, $n^{9}$ 2, pág. 359 a 368.

* Este principio, pese a ser originario de la regulación del proceso descolonizador de Africa y Amërica, fue considerado por la Corte Internacional de Justicia, en su Sentencia en la controversia entre Burkina.Faso y Mali, en 1986, como principio general del Derecho Internacional Püblico, no limitado a la sucesión por descolonización.

"El derecho de autodeterminación de los pueblos surgió en el contexto descolonizador de los 60', y por ello, en la Resolución 2625 (XXV) de la Asamblea de Naciones Unidas, se usa para proportionar la emancipaciôn de aquellos pueblos que se encontrasen bajo dominación colonial o explotación extranjera. La Comisión de Arbitraje, sin embargo, reconoció implícitamente un tercer supuesto para otorgar la autodeterminación, a saber, la violación de los Derechos Humanos por parte del estado sobre su población.
} 
A partir del estallido bélico bosnio, y coincidiendo con el inicio de la aprobación y puesta en marcha de la PESC (Política Exterior y de Seguridad Común), la UE se vio claramente desbordada e inició una serie de tentativas de gestión y propuestas de pacificación de la crisis. Dos fueron los proyectos conjuntos entre la UE/ONU en las que se presentaba una propuesta de partición. El Plan Vance-Owen (mayo de 1993), sugirió la división de Bosnia en diez cantones, tres para cada comunidad, y un décimo-Sarajevo-bajo control compartido. La Asamblea serbiobosnia rechazó la propuesta, pese a las presiones del Primer Ministro griego, Mitsokakis, del presidente de Serbia, Milosevic, y del propio Karadzic, mientras a continuación autoproclamaba la República Srpska. En septiembre del mismo año se presentó el Plan Owen-Stoltenberg según el cual, el territorio bosnio se dividiría en una Confederación de tres minirepúblicas, otorgando el 53\% a los serbiobosnios, el 30\% a los bosniomusulmanes, y el $17 \%$ a los bosniocroatas. El plan fue descartado por los bosniomusulmanes que querían una salida al Adriático. ${ }^{12}$ Este período negociador quedó congelado debido a la crudeza de los combates, y sobretodo, al protagonismo que adquirió EEUU como nuevo gestor de la crisis gracias a la firma del Acuerdo de Washington, que significó la creación de la Federación Bosniocroata en febrero de 1994, y por tanto, el cese de las hostilidades entre dos de los bandos contendientes.

Llegados a este punto, cabe destacar algunas paradojas en las que se vio sumida la comunidad internacional en su intento de encontrar una solución negociada. Por un lado, los planes de paz aceptaban implícitamente la "limpieza étnica" cometida hasta el momento, depurando las diferentes zonas para su homogenización étnico-religiosa, ya que sobre esta realidad se asentaban los diez y tres cantones sugeridos, en uno y otro plan. $Y$ por otro lado, se estaba negociando con auténticos criminales de guerra que fomentaban, alentaban, y concedían los medios para las prácticas de depuración étnica.

Igualmente, la CSCE (Conferencia para la Seguridad y la Cooperación en Europa), se encontraba durante 1992 en un proceso de mutación interna según el cual, la Conferencia se institucionalizaría como OSCE (Organización

\footnotetext{
12 Aunque del rechazo inicial del Plan Owen-Stoltenberg corrió a cargo de los bosniomusulmanes, el Presidente de los serbiobosnios declaró por la radio que la aceptación de dicho plan era "una solución transitoria hasta que la República de Serbia (Sprska) y la Herzegovina pudieran retornar a su patria madre", esto es a Serbia y a Croacia, respectivamente. En Roux M., "La Bosnie-Herzegovine en 1993. L' échec de deux plans de paix". Notes et Études Documentaires, 5006-07. 1995. Pág.77.
} 
para la Seguridad y la Cooperación en Europa), a partir de 1995. Al principio del conflicto, la CSCE se pronunció a favor de la unidad nacional y su rol se centraría en la mediación. A partir de la guerra de Bosnia, su estructura intergubernamental y su mecanismo decisional por unanimidad, no permitieron un avance definitivo colegiado cuando los diversos estados constituyentes tomaron sus decisiones unilateralmente. Algunos de ellos se inclinaron por reconocer el derecho a la autodeterminación (Principio VII) -Alemania, Austria, Bélgica, Checoslovaquia, Dinamarca, Hungría e Italia-, mientras que otros consideraron preeminentes los Principios III, IV, y V, sobre la inviolabilidad de las fronteras, la integridad territorial de los estados, y la no injerencia en asuntos domésticos- Reino Unido, Francia, Rumania, España y Turquía. ${ }^{13}$

De esta manera, y pese a que la CSCE/OSCE tildó la agresión que sufrió Bosnia en abril de 1992 como "conflicto internacional", la Organización se inhibió desapareciendo de escena hasta que se le encomendó la ardua tarea de organizar las primeras elecciones después de los Acuerdos de Dayton. Esta gran encomienda fue calificada por el IISS (International Institute of Strategic Studies) como "las elecciones más complicadas que nunca antes se hubieran celebrado en Europa, donde 49 partidos, 5 coaliciones, y 27.801 candidatos se presentaban a 7 comicios". ${ }^{14}$

El Capítulo VIII (arts. 43 a 47) de la Carta de Naciones Unidas establece la posible cooperación o vinculación de organismos regionales al sistema de Naciones Unidas, tanto para el arreglo pacífico de controversias, como para la aplicación de medidas coercitivas.

Así se dispuso que la OTAN (NATO, según las siglas en inglés), y en menor medida la UEO (Unión Europea Occidental), serían las organizaciones encargadas de hacer cumplir las disposiciones disuasorias, incluyendo aquellas que supusieran el uso de la fuerza. Con este fin se llevaron a cabo una serie de operaciones entre las que destacaron las navales conjuntas OTAN/ UEO bajo mando SACEUR (Suprem Allied Commande of Europe), las de vigilancia del cumplimiento del embargo de armas en el Adriático (operación "Sharp Guard"), y las misiones aéreas que debían dar cobertura a las zonas de exclusión aérea y a las UNPAS (misión "Deny Flight").

\footnotetext{
${ }^{13}$ Remacle E. "The Yugoslav Crisis as a Case for CSCE's Role in Conflict Prevention Management". The CSCE in the 1990': Constructing European Security and Cooperation. Baden-Baden. Nomos Verlagsgeseltchaft, 1994. Pág. 110. 4 Rules and Regulations for Elections in Bosnia-Herzegovina, publicaciön del Parlamento (provisional) de Bosniz-Heregovina y la OSCE, 24 de julio de 1996.
} 
La operación "Deliberate Force", del verano de 1995, supuso la acción efectiva de los "raids" aéreos para reducir la amenaza que pesaba sobre las "zonas seguras", para lo que ya había un mandato concreto desde mayo de 1993, como hemos comentado anteriormente.

¿Por qué la OTAN tardó entonces un año y medio en ejecutar lo previsto por el Consejo de Seguridad? A este respecto, se suponía que esta organización acataba la decisión de la ONU, y por lo tanto, la consideración civil / internacional que ésta tenía respecto a la contienda bélica. Sin duda, la poca predisposición de los países miembro de la Alianza retardó la acción, y a la práctica, tal disposición ejecutiva se desplazó al órgano decisorio de la OTAN, y concretamente, al presidente de los EEUU.

\section{El rol de algunas potencias}

En lo concerniente a la actuación de la superpotencia, el reconocimiento del nuevo estado tuvo lugar el 7 de abril de 1992, momento a partir del cual, las diferentes administraciones norteamericanas (el relevo de G. Bush por W. Clinton se produjo en enero de 1993), pasaron de una posición aislacionista, a detentar una política de contención diplomática multilateral, para terminar liderando la iniciativa de imposición de paz.

La Administración Bush consideró la desmembración de la RSFY como un "affaire" interno que se extendió a Bosnia la primavera de 1992, momento en que se acentuó su concepción maniqueista sobre la culpabilidad serbia, lo que no varió su plan de implicación en un problema presuntamente europeo.

En ese período, y respecto a la política exterior norteamericana, los objetivos estratégicos de la OTAN estaban cubiertos por Turquía y Grecia. Por otro lado, el proceso de disolución de la URSS, relegaba al espacio balcánico un valor geoestratégico secundario. En conclusión, la ausencia de intereses políticos y económicos en la zona permitía a la Administración Bush concentrarse en otras prioridades de su agenda.

Respecto a sus intereses nacionales, la cercanía de las elecciones generales, a finales de 1992, llevó al gabinete a cuestionar el alcance político de una posible intervención, considerándola en función del costo-beneficio. Contrariamente a lo ocurrido en la Guerra del Golfo, este conflicto no tenía visos de acarrear claras ventajas políticas ni económicas, ni de acrecentar la populari- 
dad presidencial gracias a una acción rápida y eficaz.

Por todo ello, desde abril de 1992 hasta bien entrado 1994, y pese al cambio de administraciones, EEUU seguiría una estrategia de contención multilateral más activa con los objetivos de evitar la extensión de la violencia a zonas adyacentes ("spill over" a Kosovo y Macedonia), integrar a Rusia en las negociaciones, conseguir más autonomía dentro de la OTAN, y menguar su presencia en las misiones de paz de la ONU. Mientras, proseguirían los envíos de ayuda humanitaria.

Los primeros indicios del cambio de estrategia datarían de 1994, cuando el gobierno de Clinton consideró que la coyuntura sobre el terreno había arrojado un nuevo equilibrio. Se había creado la Federación croata-musulmana, habían surgido las primeras disidencias entre Pale y Belgrado, a raíz de la ofensiva serbiobosnia sobre el enclave de Gorazde y del posterior rechazo del Plan de Paz del Grupo de Contacto, y en agosto los bombardeos sobre el mercado de Sarajevo habían producido 68 víctimas civiles. Por otro lado, se había integrado a Rusia en el proceso decisional de gestión de la crisis, mediante su incorporación al Grupo de Contacto y a la Asociación Para la Paz (APP), ${ }^{15}$ y en relación con las misiones de paz de la ONU, una directiva presidencial de mayo de $1994^{16}$ aseguraba un menor peso de las tropas norteamericanas en dichas operaciones.

La primera medida unilateral de implicación fue el levantamiento del embargo de armas a Bosnia, consideración que no obedeció tanto a la opinión de que el nuevo estado tenía derecho a la autodefensa, como al resultado de la toma de decisiones del presidente que se encontraba ante una tesitura doméstica que favorecía un giro en su acción exterior.

Así pues, y aprovechando una serie de circunstancias de la arena internacional que favorecían sus intereses, la Administración Clinton impulsaría diversas actuaciones con el fin de poner un contrapeso sobre el terreno bélico que posibilitara una actuación final con un escaso margen de riesgo y un alto porcentaje de beneficio.

Ya en 1995, la opinión pública se mostró escandalizada ante el avance de las tropas serbiobosnias sobre los enclaves supuestamente protegidos de Tuzla,

\footnotetext{
15 Recordemos que la creación de la Asociación Para la Paz, creada a principios de 1994, permitió a los antiguos miembros del Pacto de Varsovia, disuelto en 1991, asociarse a los 16 paises de la OTAN.

${ }^{16}$ La directiva presidencial $n^{\circ} 25$, del 2 de mayo de 1994 , condicionó el envio de "cascos azules" norteamericanos a futuras operaciones del manterimiento de la paz llevadas a cabo para proteger sus intereses nacionales, en caso de que se vieran directamente amenazados.
} 
Srebrenica y Zepa, y por los cuerpos encontrados en las fosas comunes de las minas de hierro de Ljubija, en Srebrenica, donde se contabilizaron alrededor de 8.000 cadáveres. Mientras en el campo de batalla el ejército croata-musulmán recuperaba posiciones, y la gota que derramó el vaso fue el nuevo bombardeo del mercado de Sarajevo, en verano de 1995, que en esta ocasión lanzó un balance de 37 víctimas.

El desgaste de Serbia y Montenegro producido por las medidas coercitivas de la ONU y el agotamiento de los contendientes acarreado por casi cuatro años de guerra, hacían propicia una actuación norteamericana decisiva. Máxime cuando algunas coordenadas internas, como los niveles de popularidad presidencial, las cuotas de popularidad presidencial, el descalabro electoral de las elecciones a "mid-term" de noviembre de 1994, y las críticas de sus propios compañeros de partido así como las del Congreso de mayoría republicana, ponían en duda la continuidad presidencial.

Por todo ello, y aun cuando las autoridades norteamericanas siempre mostraron una clara opinión respecto a la culpabilidad del bando serbio, el conflicto fue considerado formalmente como guerra civil, aunque las medidas tomadas desde 1994 que terminaron con los "raids" de la Alianza Atlántica desde el 30 de agosto de 1995, señalaron lo contrario. Si no se hubiera considerado un conflicto internacional, la acción sobre Bosnia habría constituido un grave crimen internacional.

Los diversos ataques aéreos selectivos, junto a la ofensiva militar terrestre basada en tropas regionales, aseguraba una acción rápida, contundente, y a todas luces victoriosa y con un número de bajas mínimo. ${ }^{17}$

A. Lake, consejero del Presidente en materia de seguridad nacional, se entrevistó con representantes europeos y norteamericanos, señalando que la contraofensiva croata y la nueva actitud estadounidense de aceptar una Bosnia dividida en dos entidades (a lo que se habían opuesto reiteradamente hasta el momento) serían elementos suficientes para que los contendientes se sentaran en la mesa de negociación. La intervención militar del 30 de agosto sirvió asimismo para encumbrar la iniciativa de EEUU -el Representante Especial de Naciones Unidas, Y. Akashi, dimitió, y R. Hooldbroke se convirtió en el

${ }^{17}$ Según las nuevas directrices trazadas por el entonces Secretario de Defensa Caspar Weinberger, EEUU no intervendría en ningún conflicto donde no pudiera llevarse a cabo una acción rápida, contundente, y con la mayor garantía de éxito. L.a llamada "Doctrina post-Vietnam" pretendía superar asi la gran reticencia popular e institucional de enviar tropas nacionales que pudiera suponer una nueva përdida de vidas norteamericanas. 
artífice de las negociaciones, y a escala doméstica, para que los congresistas norteamericanos no pudieran acusar a Clinton de debilidad o indecisión.

Concluiremos este apartado observando que los principios "realistas", seguidos durante la Guerra Fría o durante la Guerra del a Golfo "evitando la pacificación", a través de intervenciones tempranas y decisivas, fueron consideradas de poco interés nacional en Bosnia, ya que se escogió una larga estrategia de "Peace Keeping" y negociación, suficiente para que el conflicto no rebasara (efecto "Spill Over") a otras partes de la región. En este sentido, G. Gompert, ex director del Consejo de Seguridad Nacional de la Administración Bush, fue claro al declarar que "USA prometió estar al lado de Europa después de la Guerra Fría para ayudar a conservar la paz y dar soporte a la revolución democrática. Pero nuestra superioridad militar y de liderazgo no nos obliga a sacrificar a nuestros hijos cada vez que hay un conflicto (...). Por ello la mejor alternativa es capitanear una Guerra Fría contra Serbia -de duración indefinida y resultado seguro, trabajando mientras con la OTAN para proporcionar alivio a las víctimas inocentes de Bosnia". ${ }^{18}$

Sin duda Rusia fue el actor que mostró mayor decisión al considerar, el de Bosnia, como un asunto interno. Dada la turbulenta tesitura doméstica por la que atravesaba el Kremlin, -el proceso de mutación iniciado por Gorbachev en 1985 con la Perestroika y la Glasnost, la disolución del Pacto de Varsovia en 1991, la descomposición de la estructura soviética que desembocaría en la proclamación de 15 repúblicas, y las tensiones nacionalistas de la región del Cáucaso, cualquier iniciativa de acción exterior se vislumbraba extremadamente difícil.

Esta singular coyuntura histórica sumió a la potencia en el inmovilismo hasta febrero de 1994, cuando se le presentó la oportunidad de formar parte del quinteto negociador del Grupo de Contacto, abandonando cualquier resquicio del paneslavismo declarativo que le había llevado hasta entonces a ostentar posiciones proserbias. ${ }^{19}$

De este modo, e intentando convencer a Belgrado de que debía retirar su apoyo a Pale, Rusia se unió a la APP de la OTAN, que sería la encargada de propinar el bombardeo final sobre los serbiobosnios. Rusia acabaría, por tanto, acatando las decisiones del Consejo de Seguridad, es decir, admitiendo la doble naturaleza -internacional y doméstica- del conflicto.

sa Gompert D. "How to Defeat Serbia". Foreign Affairs, n² 73. Summer 1994. Pp.30 y 32.

"Habría que recordar, sin embargo, que todos los bandos en conflicto eran de etnia eslava, eso sï, con orígenes religiosos diferentes (musulmanes, católicos y ortodoxos). 
En 1991, Alemania se encontraba en pleno proceso de reunificación, lo que confería a esa potencia germana una particular situación histórica. La declaración de Croacia y Eslovenia (25 de noviembre de 1991) hizo temblar la decisión de defender la unidad del estado federal yugoslavo y suponía el incumplimiento del Memorándum de Brioni, donde se había establecido un plazo de tres meses para restablecer la unidad territorial. La CEE constató entonces (29 de noviembre de 1991), que el estado yugoslavo estaba en proceso de desmembración, e instaba a las partes a manifestar su deseo de ser reconocidos como estados soberanos.

Alemania advirtió que sólo esperaría para hacer un reconocimiento conjunto hasta el 15 de enero de 1992, y viendo que el asunto se prolongaba, decidió actuar unilateralmente reconociendo la independencia de Eslovenia y Croacia antes de Navidad, el 23 de diciembre de 1991.

Después de la retirada de D. Gensher como Ministro de Asuntos Exteriores, su sucesor $\mathrm{K}$. Kinkel se inhibió de la cuestión balcánica actuando únicamente en el contexto de la CEE/ UE.

La acción unilateral germana generó un prolífico tema de discusión política e intelectual. YD. Genscher fue puesto en tela de juicio, sobretodo después de declarar "que se había conseguido para las minorías que habitaban en Croacia, el mayor estándar de protección posible".

Algunos llegaron a ver, en dicha maniobra proteccionista, una precipitación intencionada causada por el deseo alemán de que las dos repúblicas sureñas, afines cultural, económica y geográficamente, fueran su "América Latina". ${ }^{20}$

Al estallar la guerra de Bosnia, Alemania abandonó su percepción internacional del conflicto, y en todo caso, pasó del desmarque unilateral al multilateralismo protagonizado por la CEE/UE.

Francia recogió su memoria histórica de alianza con Serbia, como contrapoder para el soporte alemán a Croacia y Eslovenia, apoyando, hasta principios de 1992, la opción federal frente a las tendencias secesionistas.

Pese a la consideración interna del conflicto, y aunque F. Mitterrand posibilitó el establecimiento temprano de un corredor aéreo para la ayuda humanitaria internacional, durante el resto de su legislatura permaneció en la sombra. Las limitaciones de sus objetivos en política exterior, respecto a una

\footnotetext{
20 La crisis de superproducción del capitalismo habría forzado a las unidades nacionales a luchar por conseguir nuevas cuotas de mercado y provisiones. Ver Amin S. "L' Ethnie e l' Assaut des Nations. Yougoslavie, Ethiopie". Ed. L' Harmattan. Paris. 1994. Pp.70-75.
} 
UEO que reemplazara a la OTAN "se hicieron dolorosamente evidentes ante la parálisis con que se abordó el tema bosnio".21

J. Chirac, mantuvo su opinión respecto a la igual culpabilidad de todas las partes en conflicto hasta bien entrado 1995. No fue hasta después del Consejo Europeo de jefes de Estado y de Gobierno (15 de junio de 1995), cuando el presidente galo fue increpado por el líder del Partido Radical Italiano, M. Penella, al comparar su actitud con las de Daladier y Chamberlain manteniendo una "AppeasementPolicy", previa al estallido de la Segunda Guerra Mundial, cuando el líder gaullista cambió de actitud. M. Panella le recordó que quizás un día no muy lejano podría verse exiliado como De Gaulle, por temor a parecer maniqueo.

La impopularidad que obtuvo la acción exterior del gobierno Chirac al emprender las pruebas nucleares en el Pacífico (Muroroa), junto a la alarma social que provocaron las ofensivas serbiobosnias durante 1995, lanzaron una nueva luz sobre el asunto bosnio confiriéndole un cariz exitoso a corto plazo. Por ello, el presidente francés emitió otro mensaje anunciando que no se opondría a la prolongación de los "raids" aéreos de la OTAN para liberar definitivamente Sarajevo. ${ }^{22}$

\section{Sobre la naturaleza civil o internacional de la guerra}

El referéndum que confirmó la decisión de la población bosnia de independizarse, tuvo lugar el 29 de febrero y el 1 de marzo de 1992, produciéndose su reconocimiento, por parte de la comunidad internacional, un mes más tarde.

Acto seguido, los efectivos el Ejército Federal Yugoslavo (90.000 soldados que pertenecían, en aquel momento, al estado todavía no reconocido de Serbia y Montenegro), permanecieron en territorio bosnio, y apoyados por las fuerzas paramilitares serbias, iniciaron una serie de operaciones de asedio contra la población no serbiobosnia.

Es decir, la comunidad serbiobosnia, ayudada por Belgrado, no acató la decisión de la mayoría de la población bosnia ni de la comunidad internacional, y empezó una guerra civil contra el gobierno de Sarajevo.

\footnotetext{
${ }^{21}$ Koslowski. G. "Bosnia Failure of the Institutions of the Balance of Power in Europe". Aussenpolitik IV, 1996. P. $361 \cdot 362$. 22 Desde ese momento J. Chirac apareció como un convencido antiserbio, de manera que ante el recrudecimiento del conflicto de Kosovo, durante los primeros meses de 1998, se avanzó a pedir la intervención sancionadora de la ONU contra el gobierno de Belgrado. Ver, por ejemplo El País, 22-05-1998.
} 
Llegados a este punto, es donde se entremezclan las razones externas (conflicto internacional) e internas (guerra civil), confiriendo al estallido bélico una naturaleza muy singular.

Atendamos a la definición de "guerra civil": "(...) conflicto que tiene lugar en un territorio de una Alta Parte contratante entre sus fuerzas armadas y fuerzas armadas disidentes o grupos organizados que, bajo la dirección de un mando responsable, ejerzan sobre una parte de dicho territorio un control tal que les permita realizar operaciones militares sostenidas y concertadas, $y$ aplicar el presente Protocolo". ${ }^{23}$

Detengámonos en los cuatro elementos constitutivos de la definición:

1.- "El conflicto tiene lugar en el territorio de un estado". Efectivamente, Bosnia era un estado recién proclamado.

2.- "Se oponen las fuerzas armadas de este estado a fuerzas armadas o grupos armados que no reconocen su autoridad". Ciertamente, las Fuerzas Territoriales Bosnias (50.000 hombres mal armados) se enfrentan al EFY y a los paramilitares serbios. Posteriormente, y durante un año, el ejército bosnio se enfrentaría a las tropas bosniocroatas.

3.- "Estas fuerzas y otros grupos armados deben estar bajo el mando de una autoridad responsable". En efecto, R. Karadjic era el líder político, R. Mladic el jefe militar de los serbiobosnios, y operaban diversas brigadas milicianas, entre las que podemos citar las lideradas por Z. Ranzjatovic ("Arkan"). A partir de 1993, el líder bosniocroata sería M. Boban.

4.- "Deben ejercer el dominio sobre una parte del territorio de dicho estado que les permita realizar operaciones militares y concertadas". Los serbiobosnios ejercen el control sobre la autoproclamada República Srpska situada al este del país, y la estrategia utilizada consistía en ocupar un territorio para abandonarlo poco después, a la suerte de los irregulares serbios que practicaban la "limpieza étnica". Igualmente, los bosniocroatas luchaban por el dominio del sur de Bosnia, desde enero de 1993 a 1994.

Por tanto, podemos afirmar fehacientemente que se trató de una guerra civil. ¿Pero se trató también de un conflicto internacional?

$\mathrm{Si}$ atendemos a una de las dos acepciones de la expresión, el Protocolo Adicional II de los Convenios de Ginebra de 1977 (art.2), se aplicaría esta definición:

${ }^{23}$ Definiciōn del protocolo Il Adicional de los Convenios de Ginebra de 1977 (art.1). 
"en caso de guerra declarada o de cualquier otro conflicto armado que surja entre dos o varias de las Altas Partes contratantes, aunque el estado de guerra no haya sido reconocido por alguno de ellos".

De hecho, en el caso de Bosnia no hay una guerra declarada entre estados, pero no se precisa una declaración formal ni una calificación jurídica de ninguna de las partes para que exista un estado de guerra.

De este modo, el hecho de que Belgrado no retirara el EPY de forma inmediata y efectiva, así como la cuestión del envío de armas de ese gobierno a Pale, podría considerarse una interferencia externa, es decir, la agresión directa e indirecta de un estado ${ }^{24}$ contra otro. (En este sentido, el mismo Karadjic acusó a Milosevic de entrometerse en los asuntos de otro estado que no era el suyo, al enemistarse con él en 1994).

En el caso de la ayuda de Zagreb a la autoproclamada entidad HerzegBosna de Bosnia, podría aplicarse similar consideración. Y en relación con la nueva guerra entre bosnio-croatas y bosnio-musulmanes, iniciada en febrero de 1993 y que duraría casi un año, su catalogación merecería también el apelativo de conflicto internacional, ya que el Consejo de Defensa Croata (HVO), liderado por M. Boban y ayudado por Zagreb, luchaba por el dominio territorial del sur del país. ${ }^{25}$ De hecho, F.Tudjman se había mostrado partidario, como su homónimo serbio, de dividir Bosnia antes de la guerra (ya desde el invierno de 1992), entre Serbia y Croacia.

En relación con el significado de "conflicto internacional", referente al potencial riesgo de implicación en la guerra de otros países con intereses en la zona, cabría destacar, al menos, dos focos de potencial balcanización. El primero, sería la región serbia de Kosovo donde el $90 \%$ de la población era de origen albanés (por tanto, religión musulmana, lengua albanesa), y el 10\% de origen serbio (es decir, religión ortodoxa, lengua serbia). Desde la anulación de la autonomía de la provincia por parte del gobierno centralista de Belgrado, en 1991, fueron surgiendo sentimientos nacionalistas que pasaron de la reivindicación de los derechos a proteger su cultura específica a tomar un cariz independentista (el UÇK o Ejército de Liberación de Kosovo surgió

\footnotetext{
24 El hecho de que Serbia y Montenegro no fueran admitidas por la Asamblea de la ONU hasta 1996, dificulta más el análisis. Y, en todo caso, Belgrado se autoconsideraba heredera de la República de Yugoslavia, lo que implicaba el reconocimiento de sus derechos y deberes.

25 En el caso de la interferencia croata en Bosnia, ambas entidades (Croacia y Bosnia) habían recibido el reconocimiento de su soberania estatal por parte de la comunidad internacional, por tanto, se trataba de un caso convencional de agresión de un estado contra otro.
} 
en 1996). Y es que la secesión de la provincia podría acarrear consecuencias de alcance incalculable, pues una patria panalbanesa supondría unir a los 1,8 millones de kosovares, a los 70.000 que vivían en la región serbia del Sandzak, más los 50.000 que habitaban en Montenegro, con los 450.000 macedonios de origen albanés, y los 3,400 millones que habitaban en Albania.

O desde el principio como zona de peligro inminente, y por ello, se procedió a un pronto despliegue de fuerzas de protección preventiva de la ONU en la frontera. Aparte de la gran proporción de habitantes de origen albanés de esta ex república yugoslava (de un 20 a un $25 \%$, según las estimaciones), la independencia de esta entidad no fue reconocida por la CEE por el veto griego. Grecia consideraba que el nombre de Macedonia pertenecía a su patrimonio histórico, y que la adopción de este nombre por parte de otro país conllevaría la reivindicación de la parte griega de Macedonia que había quedado bajo su égida en la partición de 1913. Grecia mantuvo el veto y el bloqueo económico hasta 1995. A estas fricciones podrían haberse sumado una serie de alianzas explícitas o implícitas entre los países aliados a uno u otro contendiente, que hubiera supuesto una escalada conflictiva de imprevisibles resultados.

Todo ello indica que nos encontramos ante un conflicto armado de doble naturaleza: civil e internacional, por cuanto, y si bien en esta última vertiente no existe una guerra declarada de un estado de una guerra contra otro (en el sentido decimonónico de la acción), sí existe una intromisión en Bosnia por parte de sus vecinos. Por otro lado, el evidente riesgo de balcanización suponía una clara amenaza para la paz mundial.

Los Acuerdos de Paz de Dayton de noviembre de 1995, confirman esta consideración internacional del asunto por varios motivos. Estos tratados marco adquirieron una peculiar naturaleza ${ }^{26}$ ya que se trató de unas negociaciones a tres bandas, con Izetbegovic (Bosnia), Tudjman (Croacia), y Milosevic (Serbia). Este último, actuó en representación de uno de los dos contendientes, los serbiobosnios. Igualmente, el tratado tenía como "partes firmantes", a la República de Croacia, la República Federal Yugoslava y a Bosnia-Herzegovina, lo cual no deja de ser curioso si tenemos en cuenta que lo que se acordaba era la pacificación y reconstrucción civil de uno de ellos (Bosnia). Esta singularidad nos lleva a cuestionarnos si este hecho era un reconocimiento implícito

\footnotetext{
${ }^{26}$ En relación con la doble naturaleza política y juridica de los Acuerdos de Dayton ver Vilanova P. "Los Acuerdos de Dayton: una evolución" . Anuario Cidob 1996. Fundación Cidob, 1997. Barcelona. Pp. 8-10
} 
de que dos estados (Croacia y la RFY) estaban interfiriendo, cuando no violando la soberanía de Bosnia. En este sentido, ¿tendrían los Acuerdos de Dayton un componente velado de armisticio?.

Se acordó, también, una limitación de armamento que equivaldría a la proporción de habitantes de Serbia y Montenegro, Croacia y Bosnia, según el censo de 1991. Esto es, dos estados supuestamente ajenos al país que había que pacificar, aceptaron una reducción armamentística en una ratio de $5 / 2 / 2$, respectivamente.

Los Acuerdos terminarían siendo un ejercicio de implicación tutelar "en frío" que intentaba paliar la larga indecisión de la comunidad internacional. Asimismo, la imposición de una configuración estatal liberal democrática requeriría una fuerte presencia de las instituciones internacionales (el Ombudsman sería escogido por el presidente de la OSCE, y 8 de los 14 miembros de la Cámara de Derechos Humanos serían elegidos por el Consejo de Europa, por ejemplo).

\section{Algunas conclusiones}

Después de repasar las consideraciones de algunas organizaciones y estados relativas a la catalogación civil o internacional de la guerra de Bosnia, podíamos considerar que su diferente tratamiento obedeció a sus respectivos intereses. Al ser la mayoría de las organizaciones entidades interestatales, primaron las diferencias de criterio por encima de la opinión colegiada. En el caso de la CEE/UE, que tenía voluntad intraestatal, se evidenció una política exterior común todavía embrionaria. En lo concerniente a los estados, estos basaron sus diferentes estrategias de confrontación a la crisis según iban aconteciendo las diferentes demandas domésticas y de política exterior. Así, los actores foráneos a la crisis pasaron de una actitud conservadora (consideración de guerra civil) a una más comprometida (clasificación de conflicto internacional), en agosto de 1995, dando su beneplácito a lo que iba aconteciendo sobre el terreno, hasta el nuevo statu quo que favoreció una intervención puntual y efectiva.

Bosnia mostró, una vez más, las carencias que sufre la sociedad internacional para afrontar los nuevos retos conflictivos, al no poseer un órgano representativo con el apoyo suficiente como para aplicar sus decisiones políti- 
cas, al no ser capaz de consensuar su proceso decisional, y al basar su estrategia en intervenciones reactivas más que preventivas. El caso estudiado evidenció, así mismo, las reticencias estatales a actuar a través de las organizaciones internacionales, ya que, llegado el momento, se creó un nuevo organismo gestor de la crisis -el Grupo de Contacto-. En lo relativo a la acción militar final y a la implementación de los Acuerdos de Paz, una treintena de países ${ }^{27}$ (pertenecientes o no a la OTAN) intervinieron como una coalición de aliados "ad hoc".

Cierto es que la complejidad del propio conflicto y su aparición al término de la era bipolar restaron capacidad de respuesta internacional. Había que repensar el nuevo concepto de seguridad -mucho más amplio, puesto que abarcaba tensiones culturales, medioambientales, económicas, sanitarias- y redefinir las áreas geográficas a las que se debía proteger. De resultas de todo ello, se procedió a una progresiva ampliación del concepto de seguridad colectiva que desbordaba la tradicional idea de defensa militar.

A este tenor, y para concluir, apuntar que el surgimiento, el último quinquenio, de diversos mecanismos de prevención de conflictos, ${ }^{28}$ así como la creación del Tribunal Penal Internacional permanente, en julio de 1998, arrojan un halo de esperanza para la consecución de un futuro vertebramiento internacional que permita atajar crisis venideras de forma pronta y eficiente.

\footnotetext{
27 La fuerza multinacional estaba integrada por soldados de 30 nacionalidades, 17 de los cuales no pertenecían a la OTAN. Los contendientes europeos no OTAN -Austria, Chequia, Estonia, Finlandia, Hungria, Letonia, Lituania, Rumania, Polonia, Rusia, Eslovaquia, Suecia y Ucrania, todos ellos miembros de la APP, junto con Egipto, Jordania, Malasia y Marruecos-, aportaron 10,000 hombres. EEUU contribuyó con 20.000 efectivos, y de los 30.000 aportados por la OTAN. Europa, Francia colaboró con 10.500 y Gran Bretaña con 12.500. Military Balance 1996-97. International Institute for Strategic Studies. London 1997. ${ }^{28}$ Por ejemplo, tres departamentos del Secretariado de Naciones Unidas (el de Asuntos Políticos, el de Asuntos Humanitarios, y el de Mantenimiento de la Paz) son coordinados por el Mecanismo de Alerta Rápida. En el seno de la UE, el Parlamento creó la Cêlula de Análisis de Conflictos, la Comisión impulsó la Red de Prevención de Conflictos, y el Consejo Europeo de Amsterdam acordó la creación de la Célula de Alerta Rápida dentro de la PESC.
} 